\title{
EXTERNAL DACRYOCYSTORHINOSTOMY IN FAILED CASES OF ENDONASAL DACRYOCYSTORHINOSTOMY
}

\author{
Khadija Saifuddin ${ }^{1}$, Sirisha Polkampally²
}

${ }^{1}$ Assistant Professor, Department of Ophthalmology, Osmania Medical College, Sarojini Devi Eye Hospital, Hyderabad. ${ }_{2}^{2}$ Postgraduate, Department of Ophthalmology, Osmania Medical College, Sarojini Devi Eye Hospital, Hyderabad.

ABSTRACT
BACKGROUND
The aim of this study was to evaluate the outcome of external dacryocystorhinostomy in failed cases of endonasal
dacryocystorhinostomy (EN-DCR) in patients over a period of 3 years at Sarojini Devi Eye Hospital.

\section{MATERIALS AND METHODS}

A total of 33 patients (33 eyes; 22 females, 11 males; mean age $35 \pm 9.6$ years) were included. The indications for inclusion criteria were failed endonasal DCR and NLDO, acute dacryocystitis and prior failed DCR. Females constituted 66.67\%, while males constituted $33.33 \%$. Male : female is 1:2; $60.61 \%$ eyes presented with NLDO on left side; $90.91 \%$ eyes had NLD block and $9.09 \%$ eyes had common canalicular block in failed endonasal DCR cases.

Prospective interventional case series. All patients had follow-up > 6 months. Success was defined anatomically as patency on irrigation and functionally as relief from epiphora.

\section{RESULTS}

All patients with chronic dacryocystitis were completely symptom free at final visit. Percentage of success of conventional external DCR in NLD block cases as a revision surgery in failed endonasal dacryocystorhinostomy cases at $1{ }^{\text {st }}$ week was $90 \%, 6$ th week was $80 \%$ and including common canalicular cases, the success percentage of at the end of $6^{\text {th }}$ month as $75.76 \%$.

\section{CONCLUSION}

External dacryocystorhinostomy can be attempted as a revision surgery for failed cases of endonasal dacryocystorhinostomy.

\section{KEYWORDS}

External, Dacryocystorhinostomy, Endonasal, Failed.

HOW TO CITE THIS ARTICLE: Saifuddin K, Polkampally S. External dacryocystorhinostomy in failed cases of endonasal dacryocystorhinostomy. J. Evolution Med. Dent. Sci. 2016;5(81):6034-6037, DOI: 10.14260/jemds/2016/1362

\section{BACKGROUND \\ METHODS}

Toti in 1904 described operation by opening into nasal wall with hammer and chisel, removal of nasal mucosa in the opening and medial $1 / 2$ of lacrimal sac. In 1912, Blascovics modified Toti's technique by removing the entire lacrimal sac except for a small portion surrounding the opening of the canaliculi. Kuhn in 1914 has cut nasal mucosa in horseshoe fashion leaving it attached anteriorly and suturing to the periosteum anterior to the bony opening.

Shawky Mohmood Elrosny conducted in 2010 a retrospective study on increased failure of external DCR in 65 patients and concluded that nasal endoscopic method is important in diagnosis of causes of failure of external DCR. Nasal endoscopy is essential before and after external DCR. Endoscopic endonasal DCR has some advantages over external DCR as it is a less invasive method, requires no skin incision, etc., but yet success rate of endoscopic surgery has not exceeded external DCR due to granulation tissue formation after closing osteotomy.

Financial or Other, Competing Interest: None.

Submission 16-08-2016, Peer Review 30-08-2016,

Acceptance 01-09-2016, Published 07-10-2016.

Corresponding Author:

Dr. Khadija Saifuddin,

H. No. 10, Banjara Hills,

Hyderabad-500034, Telangana.

E-mail:dvkhadijasaif@gmail.com

DOI: $10.14260 /$ jemds/2016/1362

This was a prospective, interventional case series study of all consecutive patients with a history of failed endonasal DCR, which was conducted over a period of 3 years at Sarojini Devi Eye Hospital, Hyderabad, for watering of eyes. The patients attending the OPD with prior failed endonasal DCR and diagnosed to have NLDO based on symptomatic, clinical and radiological background to relieve watering for chronic dacryocystorhinostomy were included in the study.

A detailed history regarding their complaints-onset and duration was enquired. Past history, treatment history was taken and general examination was done. Complete ophthalmic examination was done. In all patients compression over the lacrimal sac to look for tenderness and regurgitation on digital pressure (ROPLAS) and probe test for ROPLAS negative cases to evaluate for hard and soft stop assessed to diagnose NLDO. A detailed slit lamp examination along with complete nasal examination to rule out nasal pathology was done. All patients were then investigated for routine blood and urine examination.

A detailed description of procedure was given to the patients. All these patients were subjected to the conventional external DCR procedure after informed consent. Thereafter, the patients were operated by a single surgeon under local infiltration anaesthesia. Jones silicone intubation tubes were inserted in cases of a common canalicular block diagnosed on the basis of probe test using Nettleship punctum dilator and Bowmans probe. 
After 24 hours, the nasal pack as removed and syringing was done to check the patency of the lacrimal passage. Syringing was not performed in cases here, DCR combined with Jone's intubation tubes. Postoperatively, patients were given Gatifloxacin eye drops for 2 weeks, ciprofloxacin $500 \mathrm{mg}$, Ibuprofen $400 \mathrm{mg}$ and Chymoral forte tablets twice a day for five days. Syringing was done and skin sutures were removed after seven days. Silicone intubation tubes were removed at 8 weeks postoperatively and syringing was done to know the patency.

The patients were followed up after six weeks and six months. On every visit, syringing was done and all patients were followed up for a period of 6 months for complications and recurrences.

A successful outcome was defined as elimination of epiphora, absence of dacryocystitis and positive syringing test result 6 months after the surgery.

\begin{tabular}{|c|c|c|}
\hline Age (Years) & No. of Patients & Percentage \\
\hline $11-20$ & 1 & $3.03 \%$ \\
\hline $21-30$ & 11 & $30.30 \%$ \\
\hline $31-40$ & 13 & $39.39 \%$ \\
\hline $41-50$ & 6 & $18.18 \%$ \\
\hline $51-60$ & 2 & $6.06 \%$ \\
\hline Total & 33 & $100 \%$ \\
\hline Table 1: Age Group Frequency Distribution of Patients \\
\hline
\end{tabular}

The above table shows that of 33 patients, majority i.e. 13 (39.39\%) were in the age group of 31-40 years and least 1 (3.03\%) patients were in the age group of 11-20 years.

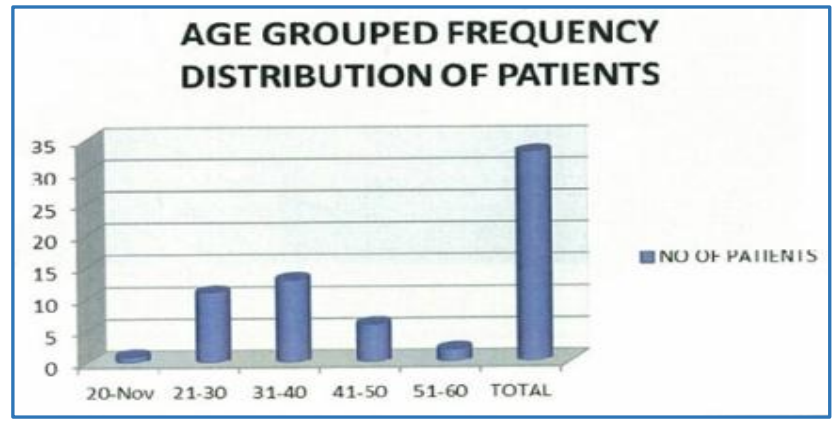

Fig. 1: Age Group Frequency Distribution of Patients

\begin{tabular}{|c|c|c|}
\hline Gender & No. of Patients & Percentage \\
\hline Male & 11 & $33.33 \%$ \\
\hline Female & 22 & $66.67 \%$ \\
\hline Total & $\mathbf{3 3}$ & $\mathbf{1 0 0} \%$ \\
\hline \multicolumn{2}{|c|}{ Table 2: Gender Distribution of Patients } \\
\hline
\end{tabular}

The above table shows that females constituted $66-67 \%$ (22), while males constituted $33.33 \%$ (11) of total 33 patients.

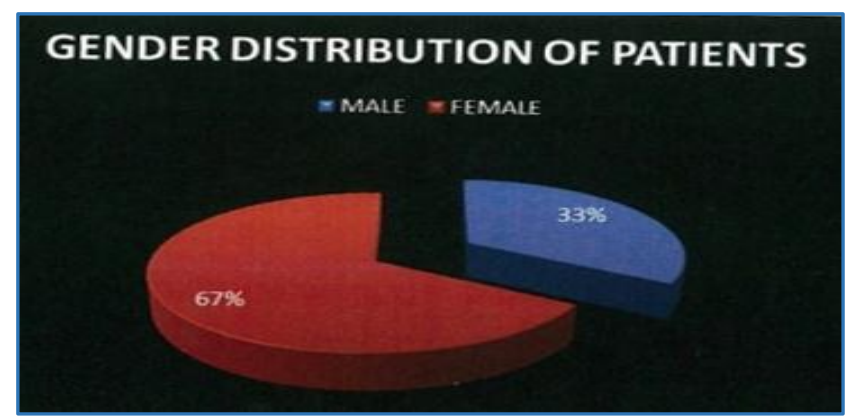

Fig. 2: Gender Distribution of Patients

\begin{tabular}{|c|c|c|}
\hline ROPLAS & No. of Patients & Percentage \\
\hline Positive & 27 & $81.82 \%$ \\
\hline Negative & 6 & $18.18 \%$ \\
\hline Total & $\mathbf{3 3}$ & $\mathbf{1 0 0} \%$ \\
\hline \multicolumn{3}{|c|}{ Table 3: ROPLAS Test } \\
\hline
\end{tabular}

On regurgitation on pressure over lacrimal sac area (ROPLAS) test, 27 (81.82\%) eyes had regurgitation positive, whereas $6(18.18 \%)$ eyes showed no regurgitation.

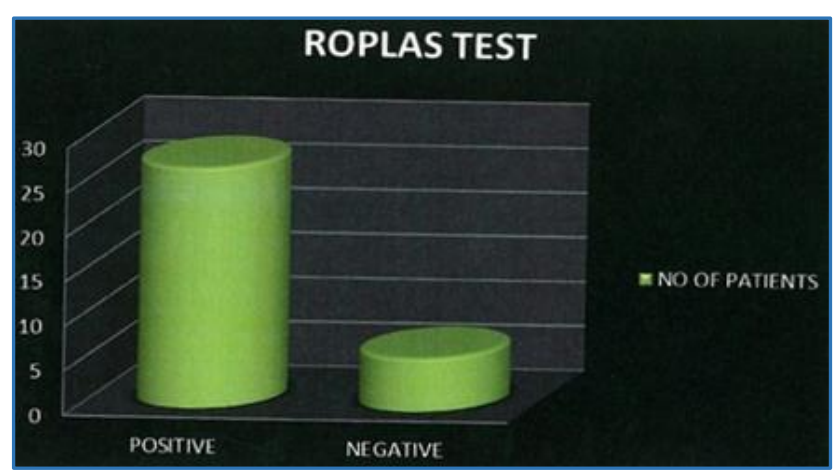

Fig. 3: ROPLAS Test

\section{RESULTS}

External DCR was performed in a total of 33 cases of previously failed endonasal DCR, at Sarojini Devi Eye Hospital, Hyderabad for a period of 3 years and the outcome evaluated.

\section{The following Observations were made}

The mean age of the group was $35 \pm 9.6$ years. A large majority $13(39 \%)$ were in the age group of 31-40 years and least 1 $(3.03 \%)$ were in the age group of 11-20 years. A large majority $22(66.67 \%)$ constituted females, while 11 (33.33\%) were males and the procedure was performed in 13 (39\%) right eyes and $20(60 \%)$ left eyes.

The indications for external DCR were patients with history of failed endonasal DCR, nasolacrimal duct obstruction with watering eyes and chronic dacryocystitis. On regurgitation on pressure over lacrimal sac area (ROPLAS) test, $27(82 \%)$ eyes had regurgitation positive, whereas 6 (18\%) eyes showed no regurgitation. Probe test was then done in cases where regurgitation test was negative and syringing showed clear fluid. It was thus shown that 3 (9\%) eyes had soft stop indicating common canalicular block and $3(9 \%)$ eyes had hard stop on probe test. Jones silicone intubation tubes were inserted in cases of soft stop diagnosed to be common canalicular block. Out of 33 eyes, 30 (90.91\%) eyes underwent external DCR, whereas $3(9.09 \%)$ eyes underwent external DCR with silicone intubation tubes.

Further, out of 30 eyes who underwent external DCR, 27 (90\%) eyes showed patency on immediate post-operative day on syringing, whereas $3(10 \%)$ eyes showed blockage. Intraoperatively, these cases revealed fibrosis of the lacrimal sac with additions. Eyes with intubation tubes were not taken up for syringing on $1^{\text {st }}$ post-operative day.

At the end of 6 weeks post-op, out of 30 cases 24 (80\%) cases showed patency, whereas $6(20 \%)$ cases had regurgitation of clear fluid on syringing; 3 cases for which intubation tubes were inserted were followed up at 8 weeks post-op and the tubes were removed. 
Out of the 30 cases who underwent conventional external DCR at the end of 6 months, $23(76.67 \%)$ cases showed patency on syringing, out of which one as a functional blockage where syringing showed patency anatomically, whereas 7 (23.33\%) cases showed blockage on syringing.

Towards the end of six months, $2(6 \%)$ cases showed both anatomical as well as functional patency four months after removing the silicone tubes, whereas $1(3 \%)$ case showed anatomical blockage due to inflammation induced fibrosis following placement of silicone tubes. At the end of 6 months, 23 cases of conventional DCR and 2 cases of DCR combined Jones intubation tubes i.e. 25 (75.76\%) cases had patent lacrimal drainage both anatomically and functionally and 8 $(24.24 \%)$ cases were termed as failure, out of which 6 (18.18\%) had failed following conventional external dacryocystorhinostomy, 1 (3.03\%) failed due to functional blockage and 1 (3.03\%) case following conventional external DCR with silicone tubes.

\begin{tabular}{|c|c|c|}
\hline Level of Block & No. of Eyes & Percentage \\
\hline NLD Block & 30 & $90.91 \%$ \\
\hline $\begin{array}{c}\text { Common } \\
\text { Canalicular Block }\end{array}$ & 3 & $9.09 \%$ \\
\hline Total & $\mathbf{3 3}$ & $\mathbf{1 0 0 \%}$ \\
\hline \multicolumn{2}{|c|}{ Table 4: Level of Block } \\
\hline
\end{tabular}

The above table shows NLD block in 90.91\% (30) and common canalicular block in $9.09 \%$ (6) patients on syringing.

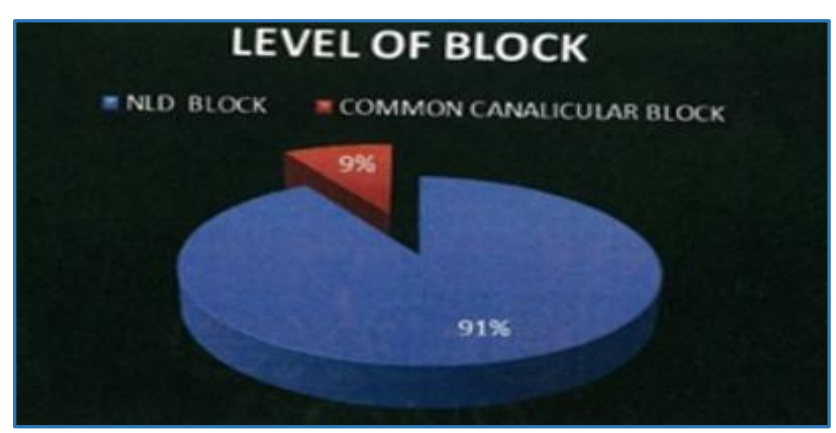

Fig. 4: Level of Block Distribution

\begin{tabular}{|c|c|c|}
\hline Syringing & No. of Eyes & Percentage \\
\hline Patent & 30 & $90 \%$ \\
\hline Not Patent & 3 & $10 \%$ \\
\hline Total & $\mathbf{3 0}$ & $\mathbf{1 0 0} \%$ \\
\hline Table 5: Results of Syringing at 1st Followup Visit \\
\hline
\end{tabular}

Out of 30 eyes who underwent external DCR, 27 (90\%) eyes showed patency on immediate postoperative day on syringing, whereas $3(10 \%)$ eyes showed blockage. Intraoperatively, these cases revealed fibrosis of the lacrimal sac with adhesions. Eyes with intubation tubes were not taken up for syringing on $1^{\text {st }}$ postoperative day.

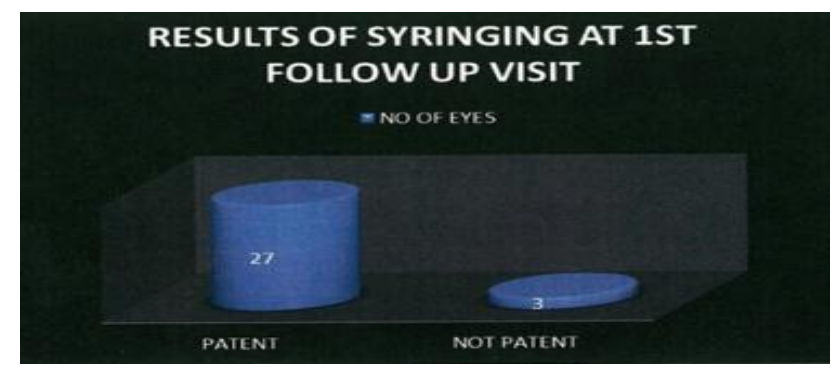

Fig. 5 - $1^{\text {st }}$ Followup Visit - Syringing Results

\begin{tabular}{|c|c|c|}
\hline Syringing & No. of Eyes & Percentage \\
\hline Patent & 24 & $80 \%$ \\
\hline Not Patent & 6 & $20 \%$ \\
\hline \multicolumn{2}{|c|}{ Table 6: Syringing at 6 } \\
th
\end{tabular}

At the end of 6 weeks post-op, out of 30 cases 24 (80\%) cases showed patency, whereas $6(20 \%)$ cases had regurgitation of clear fluid on syringing; 3 cases for which intubation tubes were inserted were followed up at 8 weeks post-op and the tubes were removed.

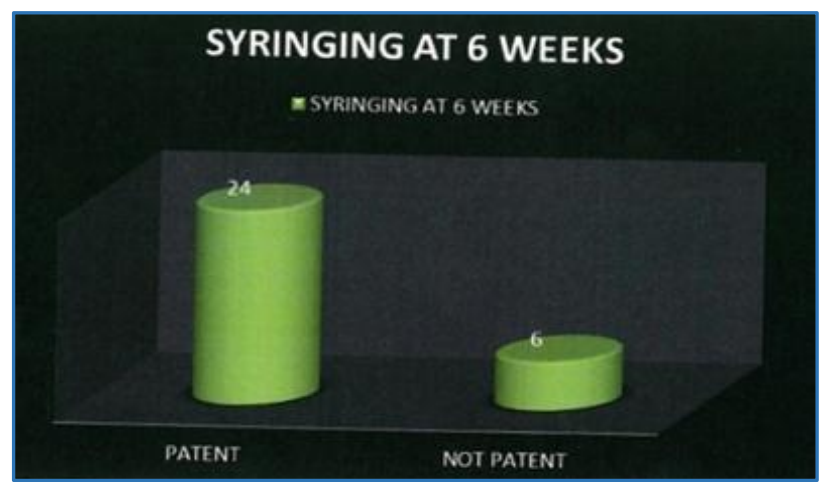

Fig. 6 - 2nd Followup Visit - Syringing at $6^{\text {th }}$ Week Postop

\begin{tabular}{|c|c|c|}
\hline EXT DCR & No. of Cases & Percentage \\
\hline Success & 25 & $75.76 \%$ \\
\hline Failure & $6+1+1=8$ & $18.18+3.03+3.03=24.24 \%$ \\
\hline Total & $\mathbf{3 3}$ & $\mathbf{1 0 0} \%$ \\
\hline \multicolumn{2}{|c|}{ Table 7: Overall Success Rate at the End of 6 Months } \\
\hline
\end{tabular}

At the end of 6 months, $25(75.76 \%)$ cases had patent lacrimal drainage both anatomically and functionally and 8 $(24.24 \%)$ cases were termed as failure, out of which 6 (18.18\%) had failed following conventional ext dacryocystorhinostomy, 1 (3.03\%) failed due to functional blockage and 1 (3.03\%) case following conventional Ext DCR with silicone tubes.

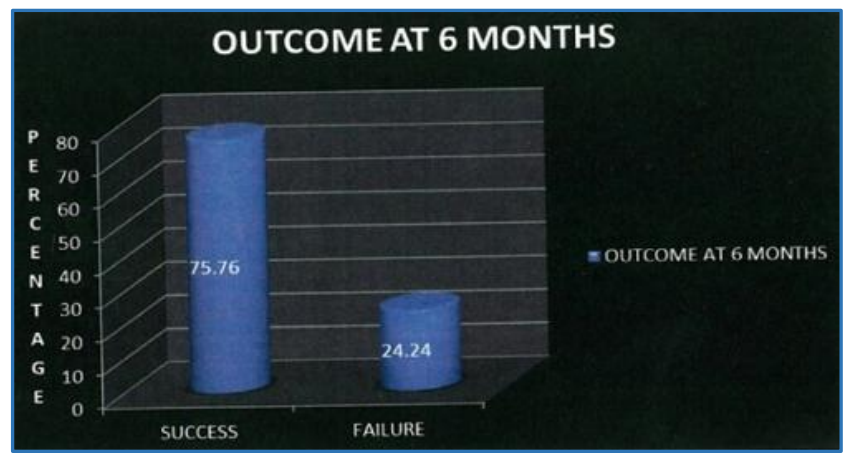

Fig. 7: Overall Success Rate at the End of 6 Months

\section{DISCUSSION}

Endoscopic endonasal DCR has some advantages over Ext DCR as a less invasive method with no skin incisions. But the success rate of the operation has not reached the level of external method. Osteotomy closure by granulation tissue has been reported as the most important reason for failure in endoscopic DCR.

Linberg$^{1}$ et al showed that lower success rate of endonasal DCR was most probably due to inability of direct suturing between nasal mucosa and mucosa of the lacrimal sac. Since 
the maintenance of patent surgical fistula requires an epithelial anastomosis within the fistula and a continuous pressure or flow of fluid, a silicone stunt was needed for some time after endoscopic procedures. An analysis of Boush et al series showed that the majority of the surgical failures occurred within four months of the endoscopic surgery. A similar finding was also seen in Kong et al study. They reported that the average onset of ostium closure after the primary operation was 6 to 26 weeks (mean 12.7 weeks). Woog et al also reported that the average onset of failure was 7.5 weeks post-op ( 2 to 14 weeks). In the present study, mean age at presentation was $35 \pm 9.6$ years with majority of patients $30-40$ yrs. (39.39\%). The youngest was 17 years old and the eldest was 55 years old. This may be due to the fact that amount of lacrimal sac secretion is less in extremes of age (Dutton 1994). In addition to that the specific infection is also more common in this age group (Mauriello JA 1992).

In our study females constituted $66.67 \%$ (22), whereas males constituted $33.33 \%$ (11). Male : female ratio was found to be $1: 2$ and our data correlated with the studies conducted by Dolman PJ. ${ }^{2}$ in 1995, Tsirbas ${ }^{3}$ in 1999 and Ben Simon ${ }^{4}$ in 1999. According to Meller, other possible cause could be anatomical narrowing of the lacrimal drainage system in females as compared to males. All patients were operated under local anaesthesia; $9.09 \%$ patients were diagnosed as common canalicular block based on probe test. Silicone intubation tubes were inserted in those cases. In our study 3 post-op follow-up visits were scheduled at $1^{\text {st }}$ week, $6^{\text {th }}$ week and 6 months. All patients were syringed at each follow-up visit to know the patency of lacrimal passage. The overall success rate of DCR was $90 \%$ at first post-op day, $80 \%$ at six weeks post-op and came down to $75.76 \%$ after six months.

Konuk 0 et al ${ }^{5}$ reported that the most common preop endoscopic finding was nasal mucosal fibrosis and synechiae and the most common cause of unsuccessful DCR surgery were inappropriate size and location of the bony ostium, fibrosis at rhinostomy site and canalicular obstruction respectively. Our study had similar findings to be the causes of failure.

Ext DCR is well established as a standard surgical procedure for the treatment of complete NLD obstruction. Advantages of Ext DCR are good intraoperative visibility inside the lacrimal sac allowing unrestricted inspection of the internal punctum and the lacrimal sac mucosa, the possibility of detecting lacrimal sac for pathology (tumours, dacryoliths) and ease of suturing mucosal flaps. Major risks being placement of cutaneous incision and wound complications (scars, infection, ectropion). The difficulties of the operation include intraoperative bleeding, obscuring visibility and prolonged operative time.
Since very limited secondary data is available on Ext DCR as a modality for failed endonasal DCR, comparisons regarding the outcome could not be made.

\section{CONCLUSION}

The following conclusions were drawn from the prospective interventional study done on 33 eyes of 33 patients; 30 of which underwent external DCR and remaining 3 underwent external DCR with intubation tubes over a period of 3 years at Sarojini Devi Eye Hospital, Hyderabad.

- Most of the patients were in 30-40 years of age group (39.39\%).

- Females constituted $66.67 \%$, while males constituted $33.33 \%$. Male : Female is $1: 2$.

- $60.61 \%$ eyes presented with nasolacrimal duct obstruction on left side.

- $\quad 90.91 \%$ eyes had NLD block and $9.09 \%$ eyes had common canalicular block in failed endonasal DCR cases.

- Percentage of success of external dacryocystorhinostomy as a revision surgery in failed endonasal dacryocystorhinostomy cases at $1^{\text {st }}$ week was $90 \%, 6^{\text {th }}$ week was $80 \%$ and at the end of $6^{\text {th }}$ month was $75.76 \%$.

- External dacryocystorhinostomy can be attempted as a revision surgery for failed cases of endonasal dacryocystorhinostomy with success rate of $75.76 \%$.

\section{REFERENCES}

1. Linberg JV, Anderson RL, Bumsted RM, et al. Study of intranasal ostium external, dacrocystorhinostomy. Arch Ophtholmol 1982;100(11):1758-62.

2. Dolman PJ. Comparison of external dacrocystorhinostomy with nonlaser endonasal dacrocystorhinostomy. Ophtholmology 2003;110(1):7884.

3. Tsirbas A, Davis G, Wormald PJ. Mechanical endonasal dacrocystorhinostomy versus external dacryocystorghinostomy. Ophtholmic Plastic and Reconstructive Surgery 2004;20(1):50-6.

4. Ben Simon GJ, Joseph J, Lee S, et al. External versus endoscopic dacrocystorhinostomy for acquired nasolacrimal duct obstruction in a tertiary referral centre. Ophtholmology 2005;112(8):1463-8.

5. Konuk O, Kurtulmusoglu M, Knatova Z, et al. Unsuccessful lacrimal surgery: causative factors and results of surgical management in a tertiary referral center. Ophthalmologica 2010;224(6):361-6. 